\title{
Case control study to identify risk factors for acute hepatitis $C$ virus infection in Egypt
}

\author{
Amr M Kandeel ${ }^{1}$, Maha Talaat ${ }^{2}$, Salma A Afifi ${ }^{*}$, Nasr M El-Sayed ${ }^{1}$, Moustafa A Abdel Fadeel ${ }^{2}$, Rana A Hajjeh ${ }^{3}$ \\ and Frank J Mahoney ${ }^{4}$
}

\begin{abstract}
Background: Identification of risk factors of acute hepatitis C virus (HCV) infection in Egypt is crucial to develop appropriate prevention strategies.

Methods: We conducted a case-control study, June 2007-September 2008, to investigate risk factors for acute HCV infection in Egypt among 86 patients and 287 age and gender matched controls identified in two infectious disease hospitals in Cairo and Alexandria. Case-patients were defined as: any patient with symptoms of acute hepatitis; lab tested positive for HCV antibodies and negative for HBsAg, HBC IgM, HAV IgM; and 7-fold increase in the upper limit of transaminase levels. Controls were selected from patients' visitors with negative viral hepatitis markers. Subjects were interviewed about previous exposures within six months, including community-acquired and health-care associated practices.
\end{abstract}

Results: Case-patients were more likely than controls to have received injection with a reused syringe $(\mathrm{OR}=23.1$, $\mathrm{Cl}$ 4.7-153), to have been in prison ( $\mathrm{OR}=21.5, \mathrm{Cl} 2.5-479.6)$, to have received IV fluids in a hospital (OR=13.8, Cl 5.3-37.2), to have been an IV drug user $(\mathrm{OR}=12.1, \mathrm{Cl}$ 4.6-33.1), to have had minimal surgical procedures $(\mathrm{OR}=9.7, \mathrm{Cl} 4.2-22.4)$, to have received IV fluid as an outpatient $(\mathrm{OR}=8, \mathrm{Cl} 4-16.2)$, or to have been admitted to hospital $(\mathrm{OR}=7.9, \mathrm{Cl} 4.2-15)$ within the last 6 months. Multivariate analysis indicated that unsafe health facility practices are the main risk factors associated with transmission of HCV infection in Egypt.

Conclusion: In Egypt, focusing acute HCV prevention measures on health-care settings would have a beneficial impact.

Keywords: Acute Hepatitis C, Risk factor, Egypt

\section{Background}

Chronic hepatitis $\mathrm{C}$ virus ( $\mathrm{HCV}$ ) infection is a major cause of chronic liver disease worldwide. The World Health Organization (WHO) estimates that $3 \%$ of the world's populations, approximately 170 million people are infected with HCV. Approximately $60 \%$ of persons with $\mathrm{HCV}$ infection develop chronic or lifelong infection with HCV. Persons with chronic HCV infection are at increased risk for development of chronic liver disease, including $5-20 \%$ who may develop cirrhosis. It is estimated that approximately $5 \%$ of infected persons may die from the consequences of long term infection (liver

\footnotetext{
*Correspondence: salma.afifi.eg@med.navy.mil

${ }^{2}$ Global Disease Detection and Response, U.S. Naval Medical Research Unit No. 3 (NAMRU-3), Naval, PSC 452 Box 5000 FPO, AE 09835, USA

Full list of author information is available at the end of the article
}

cancer or cirrhosis) [1]. HCV is spread primarily by direct contact with human blood. Risk factors most frequently associated with $\mathrm{HCV}$ transmission are transfusion of unscreened blood, injection drug use, unsafe injections, and other iatrogenic health care procedures. The development of diagnostic assays to screen blood and blood products has resulted in a remarkable reduction in transfusion-associated $\mathrm{HCV}$ infection in many developed countries [2]. Similarly, the implementation of standard precautions to prevent occupational exposure to blood has resulted in a decrease in blood-borne pathogen transmission in the health care setting [3]. Since the implementation of these measures, epidemiologic studies indicate that injection drug use is the predominant mode of transmission in developed countries [4].

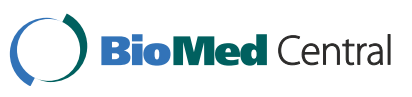


While, there are numerous studies documenting the emergence of $\mathrm{HCV}$ as an important public health problem in developing countries, there are few studies characterizing the epidemiology of $\mathrm{HCV}$ transmission in those countries. Available studies suggest that HCV transmission is complex and that transfusion of unscreened blood, unsafe injections, and invasive health-care procedures remain important causes of disease transmission. While transmission associated with injection drug use is also a well-recognized risk factor, many studies suggest that most $\mathrm{HCV}$ infections in the developing world are attributable to health care-related exposures [5].

The epidemiology of HCV transmission in Egypt has been the subject of intense study in the two decades since HCV diagnostic assays became available. Several studies have documented a prevalence of HCV antibodies ranging from 6 to $20 \%$ in the general population $[6,7]$. It is generally accepted that the high prevalence of $\mathrm{HCV}$ infection is in part attributed to parenteral antischistosomal treatment campaigns that were conducted in the 1970s. However, epidemiologic studies suggest that HCV continues to be transmitted at relatively high rates [8]. Monitoring the incidence of $\mathrm{HCV}$ infections is difficult because most infections are asymptomatic and available assays do not distinguish acute from chronic or resolved infections [9]. Prospective cohort studies monitoring HCV seroconversion among susceptible persons have identified incidence rates ranging from 3.1 to 5.2 per 100,000 $[10,11]$. Based on these studies, it is projected that 248,000 to 416,000 infections may occur each year in Egypt.

Numerous epidemiologic studies have reported diverse exposures associated with HCV infection in Egypt, including unsafe injections, health care procedures, and various community exposures. However, there are limitations to the interpretation of these data since many are based on $\mathrm{HCV}$-infected persons identified in crosssectional seroprevalence surveys and not among patients with newly acquired infections. Without well-designed studies of patients with acute disease, it is challenging to develop prevention strategies that are focused on the most important sources of ongoing transmission. This study is designed to identify risk factors among patients with newly acquired $\mathrm{HCV}$ infection, focusing on various healthcare and community-level practices. It is anticipated the results will inform health officials on key areas to formulate strategies for the prevention of HCV transmission in Egypt [12].

\section{Methods}

Between June 2007 and September 2008, case-patients and controls were enrolled from two major infectious disease hospitals in Cairo (Abassia Fever Hospital) and Alexandria (Alexandria Fever Hospital). An eligible case- patient was defined as any patient with signs and symptoms of acute hepatitis, including jaundice and the following laboratory criteria: 1. Antibodies to $\mathrm{HCV}$ (anti-HCV) (identified by EIA second generation kits), 2. Elevated transaminase (AST) levels with a minimum of 7 fold the upper normal limits [13]. 3. Negative serologic results for hepatitis B surface antigen (HBsAg), IgM antibodies to hepatitis $\mathrm{B}$ core antigen (IgM anti-HBc) and IgM-antibody to hepatitis A virus (HAV). After obtaining informed consent, 54 patients were enrolled from Abassia and 32 from Alexandria Fever hospital. The study protocol ( NAMRU3.2004.0021) was approved by the U.S. Naval Medical Research Unit No. 3 Institutional Review Board and Egyptian Ministry of Health and Population (Assurance FWA00016183) in compliance with all applicable Federal regulations governing the protection of human subjects.

Gender and age-matched controls ( \pm 5 years) were recruited from hospital visitors not living in the casepatient households. After obtaining informed consent, eligible controls were serologically screened for anti$\mathrm{HCV}$, HBsAg, IgM anti-HBc, and IgM anti-HAV. Controls with one or more positive of the above markers were excluded and replaced. Three-four sero-negative controls were recruited for each of the 86 case-patients to allow for exclusion of controls showing one or more positive antibodies for hepatitis viruses. Sample size estimates were based on calculations to detect an odds ratio (OR) of 3, assuming a frequency of single exposure of $25 \%$ among controls and $40 \%$ among patients, with a power of $80 \%$ and a significance level of $5 \%$.

\section{Serologic testing}

Serologic and AST testing was conducted at the participating hospital laboratories for case-patients; U.S. Naval Medical Research Unit\#3 (NAMRU-3) screened controls. All institutions used enzyme-linked immunoassays (ELISA) with commercial kits (Abbott Diagnostic Division) including the second generation kit for anti-HCV. AST and ALT were tested using BIOLABO (Les Hautes Rives, 02160 Maizy, France) kits.

\section{Risk factors assessment}

Trained social workers interviewed case-patients and controls using a standardized questionnaire that included demographic information, specific behaviors and activities in the 6 months prior to the case-patient hospital admission date. The questionnaire was pilot tested by trained interviewers.

Potential risk factors for $\mathrm{HCV}$ infection were categorized into healthcare-associated exposures and high risk behaviors in the community. Healthcare-associated exposures were categorized into outpatient services including type of clinic and procedures performed at outpatients 
versus hospital procedures including hospital admission and procedures performed at hospital. Community-level exposures included behaviors with the potential to transmit blood-borne pathogens such as sharing toothbrushes or sharp instruments, household contact with a person with acute or chronic hepatitis, sexual contact with multiple partners and being imprisoned over the previous six months. For each potential exposure to a risk factor, the date, duration of exposure, and location were recorded.

\section{Statistical analyses}

Univariate and matched data analyses were done with EPIINFO version 6.04 (EPI6). Individual matching by gender and age ( \pm 5 years) was performed. For variables that might influence the occurrence of acute $\mathrm{HCV}$, we calculated OR, 95\% confidence interval (CI), and the p- value.

To assess the simultaneous association between several exposure variables and case-control status, we employed conditional logistic regression models using SPSS ver 17. These models were used to estimate ORs as a measure of association to identify risk factors for $\mathrm{HCV}$ infection with attention to the exposures commonly associated with HCV transmission. Case-control status was selected as the dependent variable, while all exposure variables and potential confounders significantly related to casecontrol status in univariate analyses with $\mathrm{p}$ value $<0.05$ were selected as independent variables in these models In these models the coefficients for the independent variables were exponentiated to estimate adjusted ORs, and standard errors for the coefficients were used to construct confidence intervals for the adjusted ORs. Variables were removed in a stepwise fashion using a likelihood ratio test at each step to assess their importance in the model, until finally only those factors significant at a 0.05 level remained in the model. All statistical tests were interpreted in a two-tailed fashion to estimate $\mathrm{p}$-values and confidence intervals. The etiologic fraction in the population (EFp) for the exposures that remained in the module was calculated using OPENEPI calculator software [14].

\section{Results}

Eighty-six case-patients and 287 age and gendermatched controls were enrolled in the study; 80 controls were excluded after serologic testing for IgM anti-HAV (16), IgM anti-HBcAb (6), anti-HCV (56) and 2 who were positive for both anti-HAV and anti-HBcAb. The mean age of case-patients was $39.2 \pm 13.6$ years, with slight male predominance; approximately $50 \%$ of patients were 20-39 years of age. There was no significant difference in the age, gender and distribution of occupations among case-patients relative to controls. Case-patients were more likely to be illiterate and report past medical conditions than controls (Table 1$)$. No significant $(\mathrm{p}=0.1)$ difference in the risk of having the disease was found between the subjects with history of chronic medical conditions and those with no chronic conditions, excluding subjects who had had invasive procedures in the previous 6 months.

\section{Univariate analysis}

At least one risk factor was detected in 80 patients; 6 patients (7\%) reported they had not been exposed to any of the potential risk factors. Several outpatient medicalrelated procedures were significantly associated with acquiring acute $\mathrm{HCV}$ infections, including receiving injections with reused syringes, receiving IV fluids, minimal surgical procedures including abscess drainage, receiving dental care and wound stitches in an outpatient setting (Table 2). Visiting private, urban outpatient clinics was also associated with risk of $\mathrm{HCV}$ infection, whereas attending governmental, rural outpatient clinics was not. Although visiting a family planning clinic among females was associated with the disease, yet the 95\% CI included 1. After stratifying with attending an outpatient clinic, only receiving IV fluid, reused syringe use and minimal surgical procedures at an outpatient clinic remained significant.

In-patient hospital exposures were also associated with HCV infection, including hospitalization for any reason, receipt of IV fluids, surgery, endoscopy, receipt of a transfusion, labor for females and insertion of urinary catheters (Table 3). Among patients and controls who were hospitalized in the previous six months, using t-test for comparing 2 means, there was no significant difference regarding mean number of hospital admissions ( $p$ value $=0.07$ ) and mean length of stay at hospital ( $p$ value $=0.06$ ). Stratifying with hospital admission, only receiving IV fluid at hospital remained significant.

For community-level exposures, case-patients were more likely to report injecting drug use and recent incarceration than controls. Sharing toothbrushes, use of a public barber, injury while being shaved, and receipt of injections outside the formal health care setting were not associated with HCV infection (Table 4).

\section{Multivariate analysis for risk factors}

Logistic regression analysis identified six independent variables (Table 5). Factors were classified into three categories: hospital exposure, outpatient care and lifestyleassociated practices. Variables in the multivariate model remained significant after adjusting for occupation, education and history of chronic diseases.

We estimated the adjusted etiologic fraction in the population (EFp) for the six risk factors that entered the multivariate logistic regression model (Table 5). Results show that hospital exposures and invasive procedures 
Table 1 Demographic characteristics of the study population

\begin{tabular}{|c|c|c|c|c|c|c|c|}
\hline \multirow{2}{*}{$\begin{array}{l}\text { Demographic } \\
\text { characteristics }\end{array}$} & \multicolumn{2}{|c|}{ Case patients $n=86$} & \multicolumn{2}{|c|}{ Controls $n=287$} & \multirow[t]{2}{*}{ OR } & \multirow[t]{2}{*}{ Cl $95 \%$} & \multirow[t]{2}{*}{$P$ value } \\
\hline & Mean & SD & Mean & SD & & & \\
\hline \multirow[t]{2}{*}{ age in years } & 39.2 & $( \pm 13.6)$ & 37.6 & $( \pm 12.4)$ & 0.97 & $1.6-4.8$ & 0.3 \\
\hline & No. & $\%$ & No. & $\%$ & & & \\
\hline \multicolumn{8}{|l|}{ Age groups: } \\
\hline$<20$ & 2 & 2 & 8 & 3 & 0.8 & $0.1-4.3$ & 0.8 \\
\hline $20-29$ & 23 & 27 & 77 & 27 & 1 & $0.6-1.8$ & 0.9 \\
\hline $30-39$ & 19 & 22 & 82 & 28 & 0.7 & $0.4-1.3$ & 0.3 \\
\hline $40-49$ & 22 & 26 & 65 & 23 & 1.2 & $0.7-2.1$ & 0.7 \\
\hline $50-59$ & 14 & 16 & 42 & 15 & 1.1 & $0.6-2.3$ & 0.7 \\
\hline $60-69$ & 6 & 7 & 13 & 4 & 1.6 & $0.5-4.7$ & 0.4 \\
\hline Male & 51 & 59 & 164 & 57 & 1.1 & $0.7-1.8$ & 0.7 \\
\hline \multicolumn{8}{|l|}{${ }^{*}$ Marital status } \\
\hline Single & 19 & 22 & 81 & 28 & 0.7 & $0.4-1.3$ & 0.3 \\
\hline Married & 67 & 78 & 205 & 72 & 1.4 & $0.8-2.6$ & 0.2 \\
\hline \multicolumn{8}{|l|}{ **Education } \\
\hline Illiterate & 63 & 81 & 155 & 56 & 2.3 & $1.3-4.1$ & 0.001 \\
\hline Educated & 15 & 19 & 121 & 44 & 0.3 & $0.3-0.6$ & 0.0000 \\
\hline \multicolumn{8}{|l|}{ Occupation } \\
\hline Worker & 17 & 20 & 60 & 20 & 0.9 & $0.5-1.8$ & 0.8 \\
\hline Soldier & 2 & 2 & 0 & 0 & NA & NA & NA \\
\hline Student & 2 & 2 & 5 & 2 & 1.3 & $0.2-8$ & 0.7 \\
\hline Employee & 6 & 7 & 42 & 15 & 0.4 & $0.2-1.1$ & 0.06 \\
\hline Medical & 0 & 0 & 13 & 5 & NA & NA & NA \\
\hline Unemployed & 33 & 38 & 106 & 37 & 1.1 & $0.6-1.8$ & 0.8 \\
\hline Others & 26 & 30 & 61 & 21 & 1.6 & $0.9-2.9$ & 0.08 \\
\hline \multicolumn{8}{|c|}{ History of chronic illnesses } \\
\hline Diabetes & 10 & 12 & 32 & 12 & 1.1 & $0.5-2.3$ & 0.9 \\
\hline Schistosomiasis & 6 & 7 & 12 & 4 & 1.7 & $0.6-5.7$ & 0.3 \\
\hline Hypertension & 16 & 19 & 28 & 10 & 2.1 & $1.1-4.3$ & 0.02 \\
\hline Hepatomegaly & 5 & 6 & 0 & 0 & NA & NA & NA \\
\hline Spleenomegaly & 2 & 2 & 0 & 0 & NA & NA & $\mathrm{NA}$ \\
\hline Cirrhosis & 0 & 0 & 2 & 1 & NA & NA & NA \\
\hline Gall stones & 21 & 24 & 39 & 14 & 2.1 & $1.1-3.9$ & 0.02 \\
\hline
\end{tabular}

* data missing for one control.

** data missing for 8 cases and 11 controls.

account for the major proportion of $\mathrm{HCV}$ infections in Egypt.

\section{Discussion}

For clinical diagnosis of patients with signs or symptoms of liver disease CDC recommends testing by using anti$\mathrm{HCV}$ [15]. However anti-HCV testing detects the presence of antibodies to the virus, indicating exposure to $\mathrm{HCV}$ and cannot distinguish between someone with an active or a previous HCV infection. Before 2004 when CDC developed a case definition for acute hepatitis, all studies searching for $\mathrm{HCV}$ infection risk factors were using anti-HCV testing to identify cases, this means that using this case definition might not reflect the accurate risk factors for infection because it is unclear when the patient was exposed. This is the first study to use the case definition developed by CDC in 2004 [13] to enroll the acute newly infected cases to help identify accurately the true risk factors for $\mathrm{HCV}$ infection.

Primary prevention of $\mathrm{HCV}$ infection remains the most important strategy to prevent HCV complications. This is particularly important due to absence of vaccine and cost effective medical therapy. The impact of any effort to prevent and control $\mathrm{HCV}$ infections relies on accurate epidemiological data, particularly the identification of risk factors associated with new infections. 
Table 2 Outpatient related risk factors (within 6 months) associated with transmission of acute hepatitis C virus infection, Abbassia and Alexandria Fever Hospitals, Egypt

\begin{tabular}{|c|c|c|c|c|c|c|c|}
\hline \multirow[t]{2}{*}{ Exposure } & \multicolumn{2}{|c|}{ Cases $\mathrm{n}=86$} & \multicolumn{2}{|c|}{ Controls $\mathrm{n}=\mathbf{2 8 7}$} & \multirow[t]{2}{*}{ OR } & \multirow[t]{2}{*}{$95 \% \mathrm{Cl}$} & \multirow[t]{2}{*}{$P$ value } \\
\hline & No & $\%$ & No & $\%$ & & & \\
\hline Receiving injections & 27 & 31 & 54 & 19 & 2 & $1.1-3.5$ & 0.008 \\
\hline Receiving injection with a reused syringe & 12 & 14 & 2 & 1 & 23.1 & $4.7-153$ & $<0.000$ \\
\hline Receiving IV fluids & 30 & 35 & 18 & 6 & 8 & $4-16.2$ & $<0.000$ \\
\hline $\begin{array}{l}\text { Minimal surgical procedures (draining abscess } \\
\text { and suturing wounds) }\end{array}$ & 24 & 28 & 11 & 4.3 & 9.7 & $4.2-22.4$ & $<0.000$ \\
\hline Visiting outpatient clinic for all causes & 73 & 85 & 183 & 64 & 2.3 & $1.6-6.4$ & $<0.000$ \\
\hline Visiting a private outpatient clinic & 45 & 52 & 92 & 32 & 2.3 & $1.4-4$ & $<0.000$ \\
\hline Visiting a rural outpatient clinic & 3 & 3 & 4 & 1 & 2.5 & $0.4-13.8$ & 0.1 \\
\hline Visiting a governmental outpatient clinic & 19 & 22 & 63 & 22 & 1 & $0.5-2$ & 0.5 \\
\hline Visit urban outpatient clinic & 70 & 81 & 176 & 61 & 2.8 & $1.5-5.2$ & $<0.000$ \\
\hline Visiting a family planning clinic (females only) & $8 / 35$ & 24 & $13 / 124$ & 11 & 2.4 & $0.8-7.1$ & 0.04 \\
\hline Visiting a dental outpatient clinic & 28 & 33 & 61 & 21 & 1.7 & $1-3.2$ & 0.02 \\
\hline
\end{tabular}

Egypt, like other countries with a similar disease burden, have limited funds to support wide-scale prevention programs. Therefore, targeting and prioritizing prevention activities are essential [12].

Most seroprevalence studies in Egypt suggest community-acquired practices account for the bulk of HCV transmission in Egypt [16]. This has lead to considerable investment in communication strategies directed at the public to promote behavior changes to decrease sharing razors and toothbrushes, getting tattoos and other risky behaviors. Identifying current risk factors for ongoing $\mathrm{HCV}$ transmission is challenging, as most $\mathrm{HCV}$ infections are initially asymptomatic and available assays do not distinguish acute from chronic or resolved infections. The US Centers for Disease Control and Prevention (CDC), in association with the Council of State and Territorial Epidemiologists (CSTE), recently developed a case definition for acute hepatitis $\mathrm{C}$ to differentiate between recent infections, old infections and disease exacerbation [13]. The publication of this case definition encouraged us to conduct a case control study to explore risk factors for $\mathrm{HCV}$ infection among patients meeting the case definition of acute disease. Other methods to identify patients with newly acquired $\mathrm{HCV}$ infection include identification of patients who seroconvert from negative to positive anti-HCV antibody. Cohort studies have identified such patients in village-based studies. However, the number of patients is small and the ability to identify risk factors that are generalizable has been limited [17].

The findings from this study highlight the importance of health care exposures as a source of ongoing $\mathrm{HCV}$ transmission in Egypt. The findings suggest both outpatient procedures and as well as exposures within the hospital play a role in transmission. The risks in the outpatient settings are apparent, particularly if providers reuse injection equipment e.g. syringes and IV line. Of particular concern is the apparent break in standard precautions during minor procedures such as administration of IV fluids, suturing, and conducting minimal surgeries. This suggests that primary care staff lack the basic skills for using safe procedures such as the use of aseptic techniques, or it could be due to a shortage of

Table 3 Hospital-related risk factors associated with transmission of acute hepatitis C virus infection, Abbassia and Alexandria Fever Hospitals, Egypt

\begin{tabular}{|c|c|c|c|c|c|c|c|}
\hline \multirow[t]{2}{*}{ Exposure } & \multicolumn{2}{|c|}{ Cases $\mathrm{n}=86$} & \multicolumn{2}{|c|}{ Controls $n=\mathbf{2 8 7}$} & \multirow[t]{2}{*}{ OR } & \multirow[t]{2}{*}{$95 \% \mathrm{Cl}$} & \multirow[t]{2}{*}{$P$ value } \\
\hline & No & $\%$ & No & $\%$ & & & \\
\hline Hospital admission & 36 & 42 & 24 & 8 & 7.9 & $4.2-15$ & $<0.000$ \\
\hline Receiving IV Fluid & 22 & 26 & 7 & 2 & 13.8 & $5.3-37.2$ & $<0.000$ \\
\hline $\begin{array}{l}\text { Receive invasive procedure during } \\
\text { hospitalization }\end{array}$ & 22 & 27 & 14 & 5 & 6.7 & $3.1-14.7$ & $<0.000$ \\
\hline Surgery & 16 & 19 & 9 & 3 & 7.1 & $2.8-18.2$ & $<0.000$ \\
\hline Endoscopy & 5 & 6 & 3 & 1 & 5.8 & $2.1-31.6$ & 0.01 \\
\hline Labor (for females) & $5 / 35$ & 16 & $5 / 124$ & 4 & 4 & $1.1-11.6$ & 0.03 \\
\hline Insertion of urinary catheter & 4 & 5 & 2 & 1 & 6.9 & $1.1-55.6$ & 0.02 \\
\hline Receiving blood transfusion & 7 & 8 & 2 & 1 & 12.6 & $2.3-89.8$ & $<0.000$ \\
\hline
\end{tabular}


Table 4 Lifestyle related risk factors associated with transmission of HCV

\begin{tabular}{|c|c|c|c|c|c|c|c|}
\hline \multirow[t]{2}{*}{ Exposure } & \multicolumn{2}{|c|}{ Cases $\mathrm{n}=86$} & \multicolumn{2}{|c|}{ Controls $\mathrm{n}=\mathbf{2 8 7}$} & \multirow[t]{2}{*}{ OR } & \multirow{2}{*}{$\begin{array}{l}\text { 95\% confidence } \\
\text { limit }\end{array}$} & \multirow[t]{2}{*}{$P$ value } \\
\hline & No & $\%$ & No & $\%$ & & & \\
\hline Being imprisoned & 6 & 7 & 1 & 0.3 & 21.5 & $2.5-479.6$ & $<0.000$ \\
\hline Injecting drug use & 20 & 23 & 7 & 2 & 12.1 & 4.6-33.1 & $<0.000$ \\
\hline Sharing tooth brushes & 8 & 9 & 15 & 5 & 1.9 & $0.9-4.9$ & 0.09 \\
\hline Shaving at a barber shop (for males) & $50 / 51$ & 98 & $157 / 163$ & 96 & 1.9 & $0.2-43.1$ & 0.3 \\
\hline Wounded at barber & $21 / 51$ & 41 & $70 / 163$ & 43 & 0.9 & $0.5-1.8$ & 0.4 \\
\hline $\begin{array}{l}\text { Receiving injections outside healthcare } \\
\text { settings (home or pharmacy) }\end{array}$ & 24 & 28 & 86 & 30 & 0.9 & $0.5-1.6$ & 0.4 \\
\hline
\end{tabular}

supplies. In this study, outpatient dental care was not found to be strongly associated with $\mathrm{HCV}$ infection. Population-based or larger case-control studies are needed before any firm conclusions can be inferred regarding the role of dental care and $\mathrm{HCV}$ transmission.

The possibility of acquiring acute $\mathrm{HCV}$ infections through hospitalization for any cause has been the subject of intense study [18-20], particularly in developing countries. The rapid introduction of new technologies and invasive procedures in settings without well-developed infection control programs provides a unique ecologic niche for HCV transmission [19]. This is particularly problematic in countries like Egypt where the prevalence of $\mathrm{HCV}$ infection among hospitalized patients is high and minor lapses in standard precautions can expose health care workers and patients to HCV-infected blood or body fluids [21].

In this study, we observed that several invasive procedures were associated with acquiring new HCV infections. Prior studies have identified surgery or invasive medical procedures as main risk factors associated with transmission of $\mathrm{HCV}$ infection in developed countries $[20,22]$. In a case-control study in Italy, Mele et al. identified an invasive procedure within 6 months of acute HCV infection onset in $25 \%$ of the patients [23].
The association of HCV infection with endoscopy combined with interventional procedures such as biopsies or scelerotherapy, has also been described [24]. In a 19941999 study performed by the Italian National Hepatitis Surveillance System [23], endoscopy had been performed in $4.6 \%$ of the patients with acute HCV infection and the estimated OR for endoscopy was 2.1 (95\% CI, 1.2-3.6). This has implications for Egypt, due to the high number of patients with chronic hepatitis from schistosomiasis and chronic hepatitis $\mathrm{B}$ requiring endoscopy. Risk of transmission of HCV through endoscopy is easily eliminated when the recommended cleansing, decontamination and sterilization procedures are followed [25-27].

In addition to exposures in the health care setting, this study also identified injection drug use as an independent risk factor for $\mathrm{HCV}$ infection. In the developed world, there is accumulated evidence that injection drug use is the predominant source of new HCV infections over the past few decades which accounts for $68 \%$ and $80 \%$ of current infections $[2,28,29]$. While this study also highlights the role of injecting drug use as a risk factor for $\mathrm{HCV}$ infection in Egypt, the percentage of patients reporting injection drug use (23\%) is considerably low in comparison to developed countries. Egypt is among the African countries that recently reported experiencing

Table 5 Multivariate analysis module

\begin{tabular}{|c|c|c|c|c|}
\hline Risk factors & OR & $\mathrm{Cl}^{\mathrm{a}}$ & $\mathrm{EFp}^{\mathrm{b}}$ & $\mathrm{Cl}^{\mathrm{c}}$ \\
\hline \multicolumn{5}{|l|}{ Hospital exposures } \\
\hline Receipt of IV fluids & 13.7 & $5.6-33.5$ & 70.3 & $51.2-89.5$ \\
\hline Hospital admission & 7.8 & $4.3-14.3$ & 52.4 & $37.5-67.3$ \\
\hline Invasive procedures $^{d}$ & 4.7 & $2.8-7.9$ & 35.1 & $23.7-46.5$ \\
\hline \multicolumn{5}{|l|}{ Outpatient care } \\
\hline Abscess drainage & 33.4 & $4.2-267.9$ & 87.3 & $63.7-100$ \\
\hline Receiving injection with a Reused syringes & 23.1 & $4.7-153$ & 82 & $58.9-100$ \\
\hline \multicolumn{5}{|l|}{ Lifestyle-associated } \\
\hline IV drug user & 12.1 & $4.9-29.8$ & 67.9 & $47.5-88.5$ \\
\hline
\end{tabular}

${ }^{a}$ Confidence interval for the odds Ratio.

${ }^{b} \mathrm{EFp}$ is the etiologic fraction in the population.

c Confidence interval for the etiologic fraction in the population.

${ }^{d}$ Invasive procedures include minimal surgical procedures at outpatients and procedures at hospital. 
injection drug use. Little information regarding drug use is available in Egypt not only because it is relatively new, but also because of the lack of funds to monitor it in a systematic way [30]. This study also found that incarceration six months prior to start of illness was also a risk factor for disease. Further studies are needed to identify the specific source of $\mathrm{HCV}$ infection among incarcerated persons.

We did not identify any evidence of occupational or sexual risk factors associated with $\mathrm{HCV}$ transmission in Egypt. Numerous studies suggest that HCV transmission through occupational and sexual exposures is inefficient and that these exposures are unlikely to be major sources of new $\mathrm{HCV}$ infections, regardless of the population or geographic location [2].

Egypt is now experiencing a wave of HCV-related morbidity with increasing numbers of patients with end stage cirrhosis or hepatocellular carcinoma. The cost of treatment or liver transplantation is a strain on the national health care budget. Many patients are presenting at the peak of their productive lives with considerable impact on their families and community. Preventing ongoing transmission is of paramount importance to the health of future generations. Therefore, national strategies should focus on primary prevention by reducing the numbers of new infections. Ideally, successful treatment of infected patients has the potential to help reduce the incidence of $\mathrm{HCV}$ infection by decreasing the reservoir of infected persons who can serve as a source of transmission [10]. However, in Egypt the burden of disease is high and the capacity to treat large numbers of patients to reduce viral load is limited. This may reduce the possibility of having a meaningful impact on the reservoir of HCV-infected people in Egypt through treatment regimens.

Limitations of the study include selection of controls from the hospital visitors of the enrolled case patients or other patients in the same hospital; this may lead to selection bias because the cases and controls were not matched by place of residence.

\section{Conclusion}

The results of this study show that a number of newly identified risk factors are contributing to $\mathrm{HCV}$ transmission in Egypt. As HCV prevention remains a major challenge, and due to limited resources, activities to stop transmission should focus on safe practices in the healthcare setting. A national program to promote infection control has been implemented in Ministry of Health Hospitals since 2002, which was expanded to all general and district hospitals (356 hospitals). They have plans to expand further to primary care hospitals and units [31]. However, the healthcare system in Egypt is huge and complex and requires human and financial resources to strengthen infection control programs in settings where they exist and expand them to involve all healthcare institutions in Egypt, such as university, private, military hospitals and others. Empowering community members to refuse unsafe medical procedures could be implemented. Special attention to institutionalizing infection control programs in primary outpatient care settings is also essential.

\section{Competing interest}

Authors hereby certify that there is no conflict of interest or appearance of conflict of interest in NAMRU-3 staff professional relationships with other organizations.

\section{Authors' contribution}

AK participated in data collection and writing first draft of the manuscript. MT participated in study design, development of data collection tools, participated in supervision of the field work and did a lot of writing of the manuscript. SA supervised the field work and the data collection process, analyzed the data, and conducted the literature search. NE general advisor and provided final revision and approval of the version to be published. MA suggested and conducted laboratory techniques, organized and reported data. $\mathrm{RH}$ supervised and organized the course of the project and the manuscript. FM Study design, reviewed data collection tools, and revision and final editing of the manuscript for intellectual content before submission.

\section{Acknowledgments}

The authors acknowledge with sincere thanks and appreciation the outstanding support provided by the staff working in the infectious disease hospitals. The views expressed in this article are those of the authors and do not necessarily reflect the official policy or position of the Department of the Navy, Department of Defense, the US Government, or the Egyptian Ministry of Health.

This article fits the description stipulated by the new U.S. Copyright Act of a "United States Government work." The authors are employees of the U.S. Government and this work was prepared as part of their official duties. Title 17 U.S.C. 105 provides that 'Copyright protection under this title is not available for any work of the United States Government work as a work prepared by a military service member or employee of the United States Government as part of that person's official duties."

\section{Funding}

This work was supported by US Agency for International Development (USAID), [Work Unit no. 80000.000.000.E0022].

\section{Author details}

${ }^{1}$ Preventive and Endemic Disease Sector, Ministry of Health and Population, Cairo, Egypt. ${ }^{2}$ Global Disease Detection and Response, U.S. Naval Medical Research Unit No. 3 (NAMRU-3), Naval, PSC 452 Box 5000 FPO, AE 09835, USA. ${ }^{3}$ Division of bacterial diseases, Centers for Disease Control and Prevention, Atlanta, GA, USA. ${ }^{4}$ Centers for Disease Control and Prevention, Jakarta, Indonesia.

Received: 24 January 2012 Accepted: 1 November 2012 Published: 12 November 2012

\section{References}

1. World Health Organization: Hepatitis C Fact sheet N¹64 June 2011. 2011. http://www.who.int/mediacentre/factsheets/fs164/en/.

2. Shepard CW, Finelli L, Alter MJ: Global epidemiology of hepatitis C virus infection. Lancet Infect Dis 2005, 5:558-567.

3. Argentero PA, Zotti CM, Abbona F, et al: Regional surveillance of occupational percutaneous and mucocutaneous exposure to bloodborne pathogens in health care workers: strategies for prevention. Med Lav 2007, 98:145-155.

4. Roy K, Hay G, Andragetti R, Taylor A, Goldberg D, Wiessing L: Monitoring hepatitis $C$ virus infection among injecting drug users in the European Union: A review of the literature. Epidemiol Infect 2002, 129:577-585. 
5. Marx MA, Murugavel KG, Sivaram S, et al: The association of Health-care use and hepatitis $C$ virus infection in a random sample of urban slum community residents in Southern India. Am J Trop Med Hyg 2003, 68:258-262.

6. Frank C, Mohamed MK, Strickland GT, et al: The role of parenteral antischistosomal therapy in the spread of hepatitis $C$ virus in Egypt. Lancet 2000, 355:887-891.

7. El-Zanaty F, Ann W: Egypt Demographic and Health Survey 2008. Cairo, Egypt: Ministry of Health, El-Zanaty and Associates, and Macro International; 2009.

8. Pybus OG, Drummond AJ, Nakano T, Robertson BH, Rambaut A: The Epidemiology and latrogenic Transmission of Hepatitis C Virus in Egypt: A Bayesian Coalescent Approach. Mol Biol Evol 2003, 20:381-387.

9. Klimashevskaya S, Obriadina A, Ulanova T, et al: Distinguishing Acute from Chronic and Resolved Hepatitis C Virus (HCV) Infections by Measurement of Anti-HCV Immunoglobulin G Avidity Index. J Clin Microbiol 2007, 45:3400-3403.

10. Mohamed MK, Abdel-Hamid M, Mikhail NN, et al: Intrafamilial transmission of hepatitis C in Egypt. Hepatology 2005, 42:683-687.

11. Saleh DA, Shebl F, Abdel-Hamid M, et al: Incidence and risk factors for hepatitis $C$ infection in a cohort of women in rural Egypt. Trans $R$ SoC Trop Med Hyg 2008, 102:921-928.

12. Perz J, Alter MJ: The coming wave of HCV-related liver disease: Dilemmas and challenges. J Hepatol 2006, 44:441-443.

13. Centers for Disease Control and Prevention, case definitions of diseases under public health surveillance: 2007. www.cdc.gov/epo/dphsi/casedef/ hepatitiscacutecurrent.htm.

14. Sullivan KM, OPEN EPI calculator available: 2011. http://www.openepi.com/ Menu/OpenEpiMenu.htm.

15. Morbidity and Mortality Weekly Report: Guidelines for Laboratory Testing and Result Reporting of Antibody to Hepatitis C Virus. Recommendations and Reports: Recommendations and Reports; 2003. Vol. 52 / No. RR-3. http://www.cdc.gov/mmwr/pdf/rr/rr5203.pdf.

16. Medhat A, Shehata M, Magder LS, et al: Hepatitis $C$ in a community in Upper Egypt: risk factors for infection. Am J Trop Med Hyg 2002, 66:633-638.

17. Mohareb E, Soliman A, Aoun S, et al: Viral Hepatitis in a Bedouin population in the Sinai, Egypt. Denver, Colorado, USA: A cross sectional study. In: program and abstracts of the 51st Annual Meeting of the American Society of Tropical Medicine and Hygiene; 2002:10-14.

18. Forns $M$, Armelles $R$, Planas $R$, et al: Hospital admission is a relevant source of hepatitis C virus acquisition in Spain. J Hepatol 2008, 48:20-27.

19. Maugat $S$, Astagneau $P$, Thibault $V$, et al: Nosocomial risk factors of hepatitis C infection- A multicenter study in a hospital-based population. Rev Epidemiol Sante Publique 2003, 51:301-308.

20. Karmochkine M, Carrat F, Santos OD, Cacoub P, Raquin G: A case control study of risk factors for hepatitis $C$ infection in patients with unexplained routes of infection. J Viral Hepat 2006, 13:775-782.

21. Morbidity and Mortality Weekly Report (MMWR): Notice to Readers Recommendations for Follow-Up of Health-Care Workers After Occupational Exposure to Hepatitis C Virus. Morb Mortal Wkly Rep 1997, 46:603-606.

22. Bronowicki JP, Venard V, Botte C, et al: Patient-to-patient transmission of hepatitis C virus during colonoscopy. N Engl J Med 1997, 337:237-240.

23. Mele A, Spada E, Sagliocca L, et al: Risk of parenterally transmitted hepatitis following exposure to surgery or other invasive procedures: results from the hepatitis surveillance system in Italy. J Hepatol 2001, 35:284-289.

24. Becheur $H$, Harzic $M$, Colardelle $P$, et al: Hepatitis $C$ virus contamination of endoscopes and biopsy forceps. Gastroenterol Clin Biol 2000, 24:906-910.

25. Talaat M: el-Oun S, Kandeel A et al. Overview of injection practices in two governorates in Egypt. Trop Med Int Health 2003, 8:234-241.

26. Karsenti D, Metman EH, Viguier J, et al: Transmission by colonoscopy of hepatitis C virus: a propos of a group of 97 patients at "presumed risk". Gastroenterol Clin Biol 1999, 23:985-986.

27. Ciancio A, Manzini P, Castagno F, et al: Digestive endoscopy is not a major risk factor for transmitting hepatitis C virus. Ann Intern Med 2005, 142:903-909.

28. Alter MJ: Prevention of spread of hepatitis C. J Hepatol 2002, 36:593-598.

29. Dore GJ, Law M, MacDonald M, Kaldor JM: Epidemiology of hepatitis C virus infection in Australia. J Clin Virol 2003, 26:171-184
30. Dewing S, Plüddemann A, Myers BJ, Parry C: Review of injection drug use in six African countries: Egypt, Kenya, Mauritius, Nigeria, South Africa and Tanzania. Drugs Educ Prev Pol 2006, 13:121-137. No. 2.

31. Talaat M, Kandeel A, Rasslan O, et al: Evolution of infection control in Egypt: achievements and challenges. Am J Infect Control 2006, 34:193-200.

doi:10.1186/1471-2334-12-294

Cite this article as: Kandeel et al:: Case control study to identify risk factors for acute hepatitis C virus infection in Egypt. BMC Infectious Diseases 2012 12:294

\section{Submit your next manuscript to BioMed Central and take full advantage of:}

- Convenient online submission

- Thorough peer review

- No space constraints or color figure charges

- Immediate publication on acceptance

- Inclusion in PubMed, CAS, Scopus and Google Scholar

- Research which is freely available for redistribution 